\title{
EDITORIAL
}

\section{Diagnosing pneumonia accurately in the community - is it necessary?}

See linked article by Evertson et al.

on page 237

\section{*Claudia Newbegin ${ }^{a}$ John Macfarlane ${ }^{\mathrm{b}}$}

a General Practice Registrar (ST3), Northumbria GP Training Scheme, UK

b Consultant Respiratory Physician, Nottingham University Hospitals; Professor of Respiratory Medicine, University of Nottingham, UK (Retired)

*Correspondence:

E-mail: claudianewbegin@doctors.org.uk

16th July 2010
Problems remain regarding the diagnosis and management of respiratory tract infections (RTIs) in primary care. In this issue of the PCRJ, Evertsen et al' report a review of electronic records for adult patients consulting with RTI in an outpatient integrated health care setting in Wisconsin. They conclude that documented fever and abnormal breath sounds were the best predictors for labelling an acute RTI as pneumonia and for arranging a chest radiograph (CXR). However, whilst over $90 \%$ of those diagnosed with pneumonia had undergone a CXR, only about half were 'positive', as were nearly one in ten labelled as bronchitis or upper RTI. Furthermore, nearly every patient diagnosed as having either pneumonia or bronchitis received an antibiotic $(98.5 \%$ and $95 \%$, respectively), as did over $42 \%$ labelled with an upper RTI.

Most doctors agree that patients with pneumonia should be prescribed antibiotics and that the accurate diagnosis of pneumonia requires the defining presence of radiographic shadowing. So which patients with RTI should be X-rayed? The recently updated British Thoracic Society (BTS) Guidelines for the management of community acquired pneumonia $(C A P)^{2}$ emphasise the crucial importance of obtaining a CXR rapidly in patients ill enough to require hospital referral with suspected pneumonia in order to help confirm or refute the diagnosis. This is straightforward in a hospital setting, but for many doctors working in primary care, obtaining a CXR can add potential delays in diagnosis and management and extra workload, as well as it being costly and inconvenient for the patient. An additional problem is that consultations for acute RTI are extremely common in primary care, but only a small proportion (5-12\%) of patients will have radiographic evidence of pneumonia., Potentially, very many patients could be x-rayed to detect the few with pneumonia. For this reason, the primary care summary of the BTS Guidelines on the management of CAP, recently published in this journal, ${ }^{4}$ uses a pragmatic definition of CAP: symptoms of an acute lower respiratory tract illness together with new focal chest signs and evidence of systemic illness, with no other explanation for the illness - clinical features which have modest discriminatory powers to identify the presence of radiographic pneumonia. It is reassuring therefore that Evertson et al.' found that their doctors used the presence of rales (crackles), rhonchi and fever to make a diagnosis of pneumonia.

The European Respiratory Society (ERS) and North American guidelines ${ }^{5,6}$ suggest that patients suspected as having pneumonia in the community should receive a CXR. The argument is that clinical findings are of only limited value in diagnosing CAP, so doctors should strive to make a firm diagnosis by CXR. ${ }^{7}$ This may be an attractive argument theoretically, but is this practical and would the result really make a crucial difference in the general practitioner's (GP's) decision to start or stop antibiotics, as well as patient acceptance? The fact that nearly everyone received antibiotics in this study, irrespective of the label of bronchitis or pneumonia or the CXR result, suggests that obtaining a CXR was an ineffective management strategy for influencing antibiotic prescribing. There is other evidence that X-raying all patients with suspected pneumonia is of little value. ${ }^{3}$ It seems more sensible to X-ray selected patients with lower RTI, including those in whom the diagnosis is in doubt, those who are not improving satisfactorily, and those who are at risk of underlying lung disease such as lung cancer. ${ }^{2}$

The very high rate of antibiotic prescribing in the non-pneumonic groups in the 
Wisconsin study (groups that are thought usually to require symptomatic treatment only ${ }^{8,9}$ ) is not limited to North America. A recent pan European study ${ }^{10}$ found that the antibiotic prescribing rate for acute cough in some regions was nearly as high, although the mean prescribing rate was $53 \%$ and $21 \%$ for the lowest centres. Unnecessary antibiotic prescribing has many adverse consequences. ${ }^{11-13}$ In the UK, antibiotic prescribing rates for respiratory infections have been falling since the mid-1990s following concerted efforts to influence public and medical dependence on unnecessary antibiotic usage, and this has been linked to a secondary reduction in consultations, especially for upper RTIs. ${ }^{14,15}$ However, some patients with RTI will benefit from antibiotics and should receive them promptly, and there is some suggestion that the pendulum has swung too far away from the use of antibiotics with a resulting increase in mortality and morbidity for lower RTIs. ${ }^{16,17}$ Identifying such patients at the initial consultation is crucial. However, there would be considerable practical problems for many GPs in using a 'positive' CXR report to inform the initial prescribing decision, and most will have to continue to depend on clinical judgment aided by evidence from good studies.

Evertson and colleagues recommend further research. We agree, but what we need are well designed, prospective studies to provide evidence to help the management decision process when a patient consults with acute respiratory symptoms in the community setting. Are the symptoms and signs caused by acute infection, or is another diagnosis more likely? Does the patient warrant antibiotic therapy? If yes, which one, or a combination? For how long, and should it be started immediately, or should a delayed antibiotic prescription strategy be tried? ${ }^{18,19}$ How ill is the patient and does the patient require early review in the community or direct hospital referral? Is there an indication to arrange a CXR or other investigations now or at a later stage? What label the GP uses - pneumonia, acute bronchitis or LRTI - is less important.

\section{Conflict of interest declaration}

$\mathrm{CN}$ has no conflicts of interest.

JTM is a member of the British Thoracic Society (BTS) committee which revised the BTS Adult Community Acquired Pneumonia Guidelines published in 2009. No other relevant interests to declare.

\section{References}

1. Evertsen J, Baumgardner DJ, Regnery A, Banerjee I. Diagnosis and management of pneumonia and bronchitis in outpatient primary care practices. Prim Care Resp J 2010;19(3):237-41. http://dx.doi.org/10.4104/pcrj.2010.00024

2. Lim WS, Baudouin SV, George RC, et al. BTS guidelines for the management of community acquired pneumonia in adults: update 2009. Thorax 2009;64 Suppl 3:iii1-55. http://dx.doi.org/10.1136/thx.2009.121434

3. Macfarlane JT, Holmes WF, Macfarlane RM, et al. A prospective study of the incidence, aetiology and outcome of lower respiratory tract illness in previously well adults in the community. Thorax 2001;56:109-14. http://dx.doi.org/ 10.1136/thorax.56.2.109

4. Levy ML, Le Jeune I, Woodhead MA, Macfarlane JT, Lim WS. Primary care summary of the British Thoracic Society Guidelines for the management of community acquired pneumonia in adults: 2009 update. Prim Care Resp J 2010;19(1):21-7. http://dx.doi.org/10.4104/pcrj.2010.00014

5. Woodhead M, Blasi F, Ewig S, et al. Guidelines for the management of adult lower respiratory tract infections. Eur Resp J 2005;26:1138-80 http://dx.doi.org/10.1183/09031936.05.00055705

6. Mandell LA, Wunderink RG, Anzueto A et al. Infectious Diseases Society of America/American Thoracic Society Consensus Guidelines on the Management of Community-Acquired Pneumonia in Adults. Clin Infect Dis 2007;44:S27-72. http://dx.doi.org/10.1086/511159

7. Mandell L. Community acquired pneumonia. BMJ 2010;341:c2916 http://dx.doi.org/10.1136/bmj.c2916

8. National Institute for Clinical Excellence. Respiratory tract infections - antibiotic prescribing. Prescribing of antibiotics for self-limiting respiratory tract infections in adults and children in primary care. NICE clinical guideline 69. July 2008

9. Smucny J, Fahey T, Becker L, Glazier R. Antibiotics for acute bronchitis. Cochrane Database Syst Rev 2004;4:CD000245

10. Butler CC, Hood K, Verheij T et al. Variation in antibiotic prescribing and its impact on recovery in patients with acute cough in primary care: prospective study in 13 countries. BMJ 2009;338:b2242. http://dx.doi.org/10.1136/ bmj.b2242

11. Bucher HC, Tschudi P, Young J, et al. Effect of amoxicillin-clavulanate in clinically diagnosed acute rhinosinusitis: a placebo-controlled, double-blind, randomized trial in general practice. Arch Intern Med 2003;163(15):1793-8. http://dx.doi.org/10.1001/archinte.163.15.1793

12. Butler CC, Dunstan F, Heginbothom M, et al. Containing antibiotic resistance: decreased antibiotic-resistant coliform urinary tract infections with reduction in antibiotics prescribing by general practices. Br J Gen Pract 2007;57:785-92.

13. Goossens H, Ferech M, Vander Stichele R, Elseviers M. Outpatient antibiotic use in Europe and association with resistance: a cross-national database study. Lancet 2005;365:579-87

14. Cosby JL, Francis N, Butler CC. The role of evidence in the decline of antibiotic use for common respiratory infections in primary care. Lancet Infect Dis 2007;7:749-56. http://dx.doi.org/10.1016/\$1473-3099(07)70263-3

15. Ashworth M, Charlton J, Ballard K, Latinovic R. Variations in antibiotic prescribing and consultation rates for acute respiratory infection in UK general practices 1995-2000. Br J Gen Pract 2005;55:603-08.

16. Waterer GW. Limiting antibiotic use in Lower Respiratory Tract Infections. Have we gone too far? Chest 2009;135:1118-20. http://dx.doi.org/10.1378/ chest.08-3006

17. Winchester C, Macfarlane T, Thomas M, et al. Antibiotic prescribing and outcomes of lower respiratory tract infection in UK primary care. Chest 2009; 135:1163-72. http://dx.doi.org/10.1378/chest.07-2940

18. Arnold SR, Straus SE. Interventions to improve antibiotic prescribing practices in ambulatory care. Cochrane Database Syst Rev. 2005;(4):CD003539

19. Little P, Rumsby K, Kelly J, et al. Information leaflet and antibiotic prescribing strategies for acute lower respiratory tract infection: a randomized controlled trial. JAMA 2005;293(24):3029-35.

Available online at http://www.thepcrj.org 